\title{
LA RETÓRICA AL SERVICIO DEL USUARIO: ESTUDIO DE LOS COMENTARIOS DE LOS LECTORES EN ELPAÍS.COM, ABC.ES Y LAVANGUARDIA.ES
}

\section{Lluís Pastor y Silvia Martínez-Martínez}

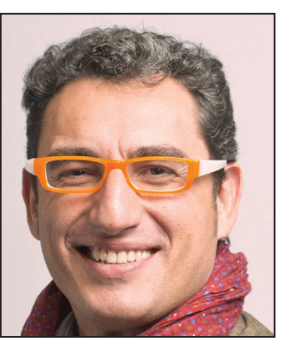

Lluís Pastor, doctor en periodismo por la Universidad Ramon Llull, es profesor y director de los Estudios de Ciencias de la Información y de la Comunicación de la Universitat Oberta de Catalunya, y director de Editorial UOC.

http://orcid.org/0000-0002-7784-0628

Universitat Oberta de Catalunya Rambla de Poblenou, 156. 08018 Barcelona, España Ipastor@uoc.edu

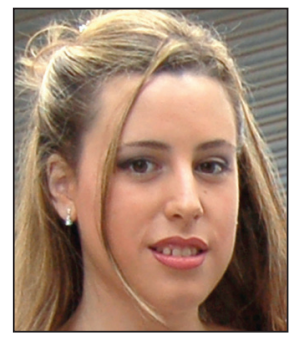

Silvia Martínez-Martínez, doctora en comunicación por la Universidad CEU Cardenal Herrera, es profesora y coordinadora de posgrado en los Estudios de Ciencias de la Información y de la Comunicación de la Universitat Oberta de Catalunya.

http://orcid.org/0000-0002-6666-7954

Universitat Oberta de Catalunya Rambla de Poblenou, 156. 08018 Barcelona, España smartinezmartinez1@uoc.edu

\section{Resumen}

El uso de la retórica en el discurso como "arte de persuasión" (Eco, 1974) ha sido objeto de reflexión y estudio. En su aplicación a la comunicación informativa, Gomis (1994) muestra cómo el periodismo desarrolla y explota una retórica propia. Con la irrupción de internet y en concreto con la apertura de la comunicación pública al ciudadano, el uso de la participación como recurso retórico cobra protagonismo al tiempo que el usuario incorpora los usos retóricos en sus contribuciones. Se analizan los comentarios de los usuarios en las noticias de portada de Elpaís.com, Abc.es y Lavanguardia.es con un doble objetivo: detectar patrones de participación (tanto en referencia al volumen como a la presencia de temas populares que generan un mayor número de contribuciones) y observar los usos retóricos que se registran en los comentarios de los lectores para definir el tipo de participación predominante.

\section{Palabras clave}

Retórica, Participación, Comentarios, Diarios digitales, Periodismo online, España.

Title: Rhetoric at the service of users: analysis of reader comments of Elpaís.com, Abc.es and Lavanguardia.es

\begin{abstract}
The use of rhetoric as the "art of persuasion" in discourse (Eco, 1974) has been the subject of reflection and study. As applied to informative communication, Gomis (1994) shows how journalism develops and operates its own rhetoric. With the arrival of the Internet and specifically with the opening of public communication to the average citizen, the use of participation as a rhetorical resource gains prominence and at the same time users add the rhetorical uses to their contributions. This article focuses on user comments in the front page of ElPaís.com, Abc.es and Lavanguardia.es with two objectives: to detect patterns of participation (in reference to the volume and to the presence of popular topics that generate a greater number of contributions) and to observe the rhetorical uses that are included in the comments of the readers to determine the predominant kind of participation.
\end{abstract}

\section{Keywords}

Rhetoric, Participation, Comments, Digital newspapers, Online journalism, Spain.

Pastor, Lluís; Martínez-Martínez, Silvia (2013). "La retórica al servicio del usuario: estudio de los comentarios de los lectores en Elpaís.com, Abc.es y Lavanguardia.es". El profesional de la información, marzo-abril, v. 22, n. 2, pp. $113-121$.

http://dx.doi.org/10.3145/epi.2013.mar.03 


\section{Periodismo digital y participación del público}

La conectividad (De-Kerckhove, 1999) y la interactividad que permite la arquitectura redistribuida de internet (Newhagen; Levy, 1996) explican la mayor horizontalidad y apertura de la comunicación pública. En el entorno mediático esta evolución tiene efectos en la relación con la audiencia y en los contenidos informativos. Asistimos al desarrollo de una cultura participativa (Jenkins, 2008) favorecida por la expansión de la filosofía 2.0.

La participación del público en la prensa digital ha despertado interés convirtiéndose en un tema destacado (Allan; Thorsen, 2009; Haas, 2010; Papacharissi, 2009; Schaffer, 2010). La significación de la participación al reforzar el vínculo de afecto y pertenencia del lector que "hace público su compromiso con el diario" (Pastor, 2004, p. 172) explica este interés. La posibilidad de aumentar la fidelización y el tráfico llevan a los medios a incorporar espacios de participación (Masip et al., 2010).

Varios estudios han puesto de relieve las limitaciones y deficiencias o peligros de la participación en términos de volumen (Bergström, 2008) y de calidad de la contribución (Singer; Ahsman, 2009; Díaz-Noci et al., 2010; Lasica, 2002). Aunque se observa atomización de opciones, se registra el protagonismo de la participación en respuesta a textos realizados por periodistas (Gillmor, 2004) frente a las posibilidades de creación de nuevos contenidos (Domingo et al., 2008). Esta realidad coincide con la señalada por Hermida (2011) al analizar el periodismo participativo, ya que de las cinco etapas que identifica en el proceso de producción, el mayor número de opciones participativas está en la de interpretación. El comentario es la opción que mayor popularidad registra frente a otras herramientas interactivas (Martínez-Martínez, 2011a) y se enmarca precisamente en esa fase. Se trata del "más penetrante, y quizá fundamental, nivel de participación" (Bowman; Willis, 2005, p. 34) y supone la puesta en práctica del tipo de relación que Nip (2010) denomina "de respuesta ciudadana". Actúa además como un indicador de noticiabilidad y puede influir en la agenda pública (García-de-Torres et al., 2009) si, siguiendo a Gomis (1991), "la noticia surge con el comentario". Las preferencias del usuario en forma de listados de lo más participado permiten conocer los intereses de la audiencia y cuestionar la figura de gatekeeper (Singer, 2006) frente al rol que el usuario ejerce de gatewatcher (Bruns, 2008).

\section{Los comentarios de los lectores pueden gestionarse mediante la moderación y por la existencia de una normativa espe- cífica}

\section{Ambivalencias ante la opción de comentar los contenidos}

La investigación sobre comentarios de los usuarios en medios digitales informativos es escasa (Abdul-Mageed, 2008). Los trabajos realizados muestran limitaciones en el uso y divergencias en términos de percepción. Reich (2011) muestra cierta ambivalencia en la valoración que hacen los periodistas: reconocen beneficios para el discurso público pero también destacan la presencia de contribuciones negativas y el trabajo que les genera. La investigación de Ruiz et al. (2010) sobre comentarios en diarios digitales catalanes demuestra que las deficiencias del diálogo se registran por la fragmentación y la falta de pluralidad, argumentación y respeto. Concluye que los mecanismos de control resultan insuficientes pues no impiden la presencia de contenidos no deseados. En un estudio sobre los comentarios en The guardian, Le monde, The New York times, El país y La republica, se observa que los distintos modelos de moderación tienen poco impacto en la calidad del debate (al contrario de lo que ocurre con la influencia ejercida por el contexto cultural) y que la adhesión a la línea ideológica del medio es la tendencia mayoritaria entre las contribuciones de los ciudadanos (Ruiz et al., 2011).

Aunque la moderación se presenta como "garantía para el lector" (Fondevila-Gascón, 2012), las protestas de los usuarios sobre este sistema de regulación son constantes. En Elpaís.com por ejemplo, el defensor del lector se hace eco de esas quejas que van desde la censura injusta hasta la existencia de modelos laxos de control (Delclós, 2012; Pérez-Oliva, 2009).

Otra vía de gestión de comentarios es la presencia de una normativa específica. Ésta se registraba en el $60 \%$ de la

\begin{tabular}{|l|l|l|}
\hline \multirow{2}{*}{ Tipo } & \multicolumn{1}{|c|}{ Recurso retórico } & \multicolumn{1}{c|}{ Descripción } \\
\cline { 2 - 3 } & \multicolumn{1}{|c|}{ Tipo de comentario } \\
\hline \multirow{3}{*}{ Participación } & $\begin{array}{l}\text { Ayuda a que el lector se sienta incorporado y reflejado en } \\
\text { la publicación, bien a través de los contenidos que se publi- } \\
\text { can o al permitir vías directas de intervención. }\end{array}$ & $\begin{array}{l}\text { Comentarios en los que el lector informa o expresa su opinión } \\
\text { relacionada con el acontecimiento o el personaje que protagoni- } \\
\text { za la noticia. }\end{array}$ \\
\hline \multirow{5}{*}{ Intólogo } & $\begin{array}{l}\text { Se trata del modo que tienen los medios para dirigirse al } \\
\text { público. Predomina la fragmentación del mensaje y la cons- } \\
\text { trucción de la conversación a partir de la confrontación. }\end{array}$ & $\begin{array}{l}\text { Mensajes en respuesta a un comentario/s que otro/s lector/es } \\
\text { ha/n realizado previamente. Resulta clave la actitud que se pro- } \\
\text { yecta respecto a la contribución previa a la que hace referencia y } \\
\text { los argumentos empleados. }\end{array}$ \\
\hline $\begin{array}{l}\text { Permite establecer una nueva vía de relación entre la } \\
\text { publicación y sus lectores en la que la intervención de la } \\
\text { audiencia se centra en el medio: desde la valoración de su } \\
\text { línea editorial hasta la corrección de algún contenido. }\end{array}$ & $\begin{array}{l}\text { Los comentarios reflejan la participación y el diálogo pero aluden } \\
\text { o hacen referencia a la publicación (tanto al medio como a la } \\
\text { noticia en particular). }\end{array}$ \\
\hline
\end{tabular}

Tabla 1. Tipos de comentarios de los usuarios según el recurso retórico utilizado. Elaborado a partir de Gomis (1994, p. 63) y Pastor (2004, pp. 86-95; 2006; 2010) 


\begin{tabular}{|c|c|c|}
\hline \multirow{3}{*}{$\begin{array}{l}\text { Comentarios de } \\
\text { participación }\end{array}$} & Información & -- \\
\hline & \multirow{2}{*}{ Opinión } & Positiva \\
\hline & & Negativa \\
\hline \multirow{7}{*}{$\begin{array}{l}\text { Comentarios de } \\
\text { diálogo }\end{array}$} & \multirow{4}{*}{ Acuerdo $^{3}$} & Ayuda \\
\hline & & Apoyo \\
\hline & & Refuerzo \\
\hline & & Resolución \\
\hline & \multirow{3}{*}{ Desacuerdo } & Aclaración \\
\hline & & Disconformidad \\
\hline & & Descalificación \\
\hline \multirow{6}{*}{$\begin{array}{l}\text { Comentarios de } \\
\text { intervención }\end{array}$} & \multirow{2}{*}{ Referida al diario } & Positiva \\
\hline & & Negativa \\
\hline & \multirow{2}{*}{ Referida al artículo } & Positiva \\
\hline & & Negativa \\
\hline & \multirow{2}{*}{$\begin{array}{l}\text { Referida a un aspecto } \\
\text { específico }\end{array}$} & Positiva \\
\hline & & Negativa \\
\hline
\end{tabular}

Tabla 2. Categorías y subcategorías para establecer una tipología de comentarios de las noticias. Elaborado a partir de los trabajos de Pastor sobre cartas al director $(2004 ; 2006 ; 2010)$

muestra estudiada en 2009 por Martínez-Martínez (2012). Algunos medios analizados limitaban con la selección de contenidos aquellas informaciones abiertas al comentario. Sólo Público.es, Lavanguardia.es, Diariovasco.com y Elcorreodigital.com permitían comentar todas las noticias de portada, de "Política", "Internacional" y "Gente/ Estilo". Mayor control se observaba en Elpaís.com, Larazón.es y elperiódico.com mientras que Abc.es se encontraba en una posición intermedia. Aunque los criterios editoriales afectan a la apertura a la participación e influyen "en la visibilidad de los temas" (García-de-Torres et al., 2009), varios estudios demuestran una mayor concentración de la participación en noticias vinculadas con "Internacional", "Política" y en aquellas que tratan acontecimientos de gran magnitud (García-de-Torres et al., 2009; Abdul-Mageed, 2008; Martínez-Martínez, 2011b).

\section{La participación como uso retórico y usos retóricos en la participación}

Junto a las políticas editoriales, las estrategias de reconocimiento del contenido generado por el usuario (user generated content, UGC) en el medio (García-de-Torres, 2012) condicionan la visibilidad de los comentarios. El lay out -diseño o disposición de la página- se ve alterado con la irrupción de los listados de noticias más comentadas y con la publicación del número de comentarios recibidos junto al titular en portada. Son recursos que buscan mostrar la opción de participar en el medio pero también captar la atención del lector. Es un nuevo reclamo que se añade a otros heredados de la prensa convencional (imágenes, titulares, colores...). Se incorpora a aquellos elementos que Gomis (1994) denominaba retórica de la emoción y se suman al resto de usos retóricos empleados en el texto para lograr el éxito en la comunicación: retórica de la certeza, de la alarma, de la personificación, del presente, del diálogo y de la participación ${ }^{1}$.

En aplicación a contenidos creados por el público y concretamente en las cartas al director, Pastor $(2004 ; 2006 ; 2010)$ propone una tipología de mensajes basada en esos usos retóricos (Gomis, 1994) y distingue entre cartas de participación, de diálogo y de intervención (que emplean un recurso retórico híbrido de los anteriores). Si, siguiendo a García-deTorres (2012, p. 60), las cartas constituyen un antecedente del UGC e incluso pueden situarse como el puente hacia "el periodismo de interactividad comunicativa" al permitir contenido creativo, aquí se plantea la traslación de este tipo de mensajes a los comentarios de los usuarios en diarios digitales (ver tabla 1).

El comentario es la opción que mayor popularidad registra frente a otras herramientas interactivas

\section{Metodología}

Este artículo se centra en el estudio de los comentarios de los lectores en las noticias. Reich (2011, p. 100) señala que hay cinco aproximaciones al estudio de los comentarios: aspectos éticos; estudio de las personas que hay tras ellos; análisis de la evolución; análisis de las percepciones y la gestión de la participación; y estudio de los aspectos retóricos y aquello que genera más participación. Nuestro trabajo se sitúa en el quinto enfoque.

Las preguntas de investigación se relacionan con el tipo de participación del público y la influencia del tema en el volumen de comentarios registrados. Para dar respuesta a estas preguntas se toman como referencia trabajos anteriores sobre la participación en las cartas al director (Pastor, 2004; $2006 ; 2010$ ) y se combinan dos modelos de análisis. Se realiza una aproximación cuantitativa a los contenidos participados y específicamente a las cinco piezas más comentadas de las portadas ${ }^{2}$ de los diarios digitales. El análisis cualitativo se practica en dos niveles: el primero permite establecer los temas de las tres informaciones con más comentarios y, en un segundo nivel, se realiza un análisis de discurso y lingüística textual basado en la detección del tema, tesis y actitud de los 50 últimos comentarios de las noticias con mayor participación para distinguir los mensajes en función de las categorías y subcategorías de la tabla 2.

Tabla 3. Participación en las noticias de portada 


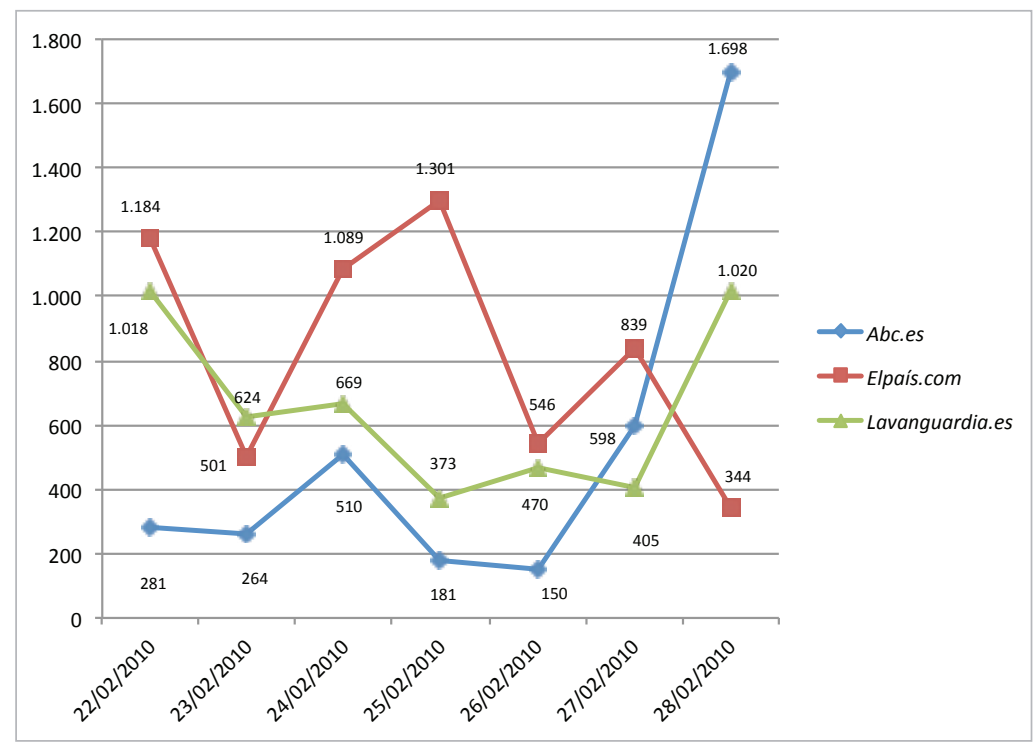

Gráfico 1. Comentarios de las cinco noticias de portada más participadas (suma por día y diario)

La selección de cabeceras se basó en criterios de calidad (Merrill, 1999) y diversidad ideológica. La muestra quedó constituida por Abc.es, Elpaís.com y Lavanguardia.es ${ }^{4}$. El análisis se realizó del 22 al 28 de febrero de 2010 entre las 23:00 y las $24: 00^{5}$. Como hipótesis de partida se espera confirmar hallazgos previos en términos de significación y predominio de noticias participadas en temas relacionados con "Política" (Abdul-Mageed, 2008; Martínez-Martínez, 2011b; García-de-Torres et al., 2009) y, partiendo de la fragmentación registrada por Ruiz et al. (2010), observar mayor presencia de mensajes de participación frente al diálogo.

\section{Resultados}

Durante el análisis se contabilizan 401 noticias en portada. Sólo en el $47,4 \%$ de las mismas se registra la opción de comentar. El mayor porcentaje de noticias comentadas se da en Lavanguardia.es (75,8\%). Los resultados muestran divergencias en los mapas de participación de los diarios analizados (condicionados por las estrategias de los medios que deciden en qué noticias permiten o no comentarios).
No existen coincidencias en la frecuencia ni correspondencia entre número de noticias en portada y el porcentaje de ellas con la opción de comentar. No obstante Lavanguardia.es, con una apertura de la participación en las noticias más elevada (una media por día de 17 informaciones) presenta también una selección más amplia de contenidos en la home (media de 22 noticias). Si se analizan las cinco informaciones diarias con más mensajes del público, se observa que Elpaís.com es el diario que más aportaciones recibe con una media de 829 comentarios al día.

Atendiendo a las tres informaciones más participadas por día y cabecera, "Política" es el tema más popular con un elevado número de noticias situadas entre las más comentadas $(47,6 \%$ en Lavanguardia.es, $50 \%$ en Elpaís.com y $42,9 \%$ en Abc.es). Las diferencias se registran en niveles inferiores: en Lavanguardia.es la segunda posición la ocupa

"Sociedad" (23,8\%) y en Elpaís.com y Abc.es es "Internacional" ( $25 \%$ y $28,6 \%$ respectivamente). Resulta significativo el reducido número de noticias entre las más comentadas correspondientes a las secciones de "Economía", "Cultura", "Deporte" o "Televisión". Por último "Meteorología”, "Educación", "Religión" y "Ciencia" no obtienen representación en este ranking.

Los resultados apuntan hacia la influencia de las estrategias editoriales de los diarios y el interés de los usuarios por determinados contenidos

Se observan diferencias en los acontecimientos que más interés generan en la audiencia de cada diario (tabla 4). La Ley del aborto se encuentra entre las noticias más comentadas en Abc.es y Elpaís.com. En Lavanguardia.es destaca una noticia sobre la consulta independentista, si bien el interés por

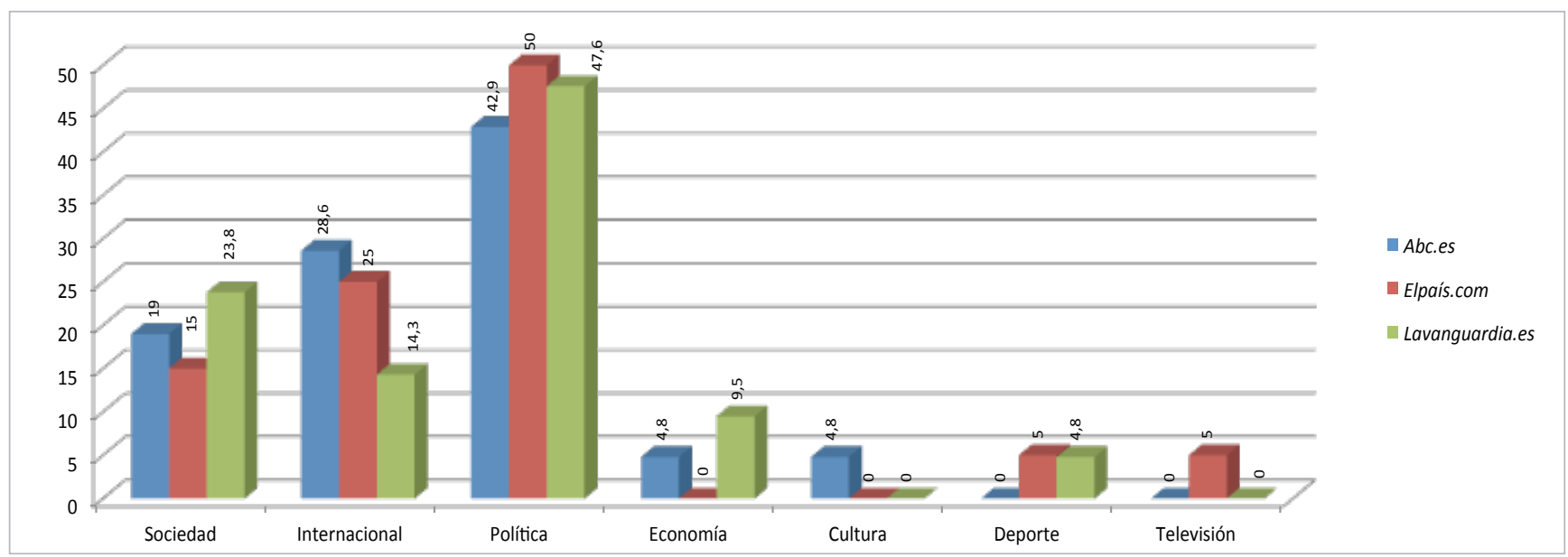

Gráfico 2. Distribución temática de las noticias de portada más participativas (\%) 
el debate nacionalista impregna también los comentarios de los lectores del diario en la única noticia de "Deportes" de este listado. La repercusión del terremoto en Chile despierta el interés de los lectores de los tres diarios y se sitúa entre las noticias más comentadas.

El análisis aplicado sobre los 50 últimos comentarios registrados en estas 21 noticias (un total de 1.046 mensajes) muestra que en su mayoría corresponden al tipo "participación": suman el 67,3\% en Abc.es, 69,4\% en Lavanguardia.es y $75,4 \%$ en Elpaís.com. El estudio de los mensajes clasificados como "diálogo" muestra que los mayores porcentajes se registran en Abc.es (31,8\%) y Lavanguardia.es (30\%). Elpaís. com presenta datos inferiores $(23,7 \%)$. Los comentarios de intervención son residuales (sólo se contabilizan 8 mensajes).

Entre los comentarios que responden a una retórica de la participación, destaca su presencia (94\%) en la noticia sobre el terremoto de Chile en Elpaís.com (n. 13). Este tema es el que genera el mayor número de comentarios de información, en este caso en Lavanguardia.es (el 54\% de los analizados en esta noticia). Se encuentran explicaciones que permiten conocer detalles del suceso o intervenciones que cuentan en primera persona su experiencia, por ejemplo:

- " [...] los terremotos de más de 5 grados en la escala Richter van en aumento en todo el Círculo de Fuego [...]" (Climategate).

- "[...] se sintió muy fuerte, se movió todo, cayeron de las paredes los cuadros y los animales avisaron antes, corriendo [...]" (Maru).

La mayor presencia de comentarios de participación catalogados como "opiniones" se registra en términos naturales en Elpaís.com (201 comentarios) y en Abc.es en términos porcentuales sobre el total de mensajes de participación $(85,0 \%)$. En todos los diarios las opiniones negativas son mayoría: el $69,1 \%$ de los mensajes encuadrados en una retórica de la participación en Abc.es, 58,3\% en Elpaís.com y $54,3 \%$ en Lavanguardia.es. En este último se encuentra la noticia (n. 19) con mayor número de comentarios con opinión negativa y en ellos las críticas se centran en la gestión política y en el comportamiento de algunos grupos de inmigrantes, por ejemplo:

- "[...] nos quejamos de nuestros políticos por la desidia/ incompetencia por no gestionar este tema [...]" (Adolfo).

- "Los gitanos rumanos están dando muchos problemas, hasta el punto de hacer peligrar la convivencia con el colectivo de extranjeros [...]" (Emilio).

Se puede hablar de un bajo índice de comunidad, es decir, de la escala que mide la relación del usuario con el medio y con el resto de lectores

Las opiniones positivas, aunque minoritarias en los comentarios de participación, se registran en mayor medida en Elpaís.com (17,8\%). La mayoría se presentan en la noticia sobre el seísmo de Chile. Junto a los comentarios que transmiten ánimo y esperanza se encuentran los que destacan aspectos positivos o alaban algún rasgo:

- “¡Bravo Chile! Casi 9 grados y un número de víctimas, que aunque lamentable, es muy reducido [...]" (JVC).

\begin{tabular}{|c|c|c|c|}
\hline No & Fecha & Titular & Comentarios \\
\hline \multicolumn{4}{|c|}{ Abc.es } \\
\hline 1 & $22-02-2010$ & El PP acusa al Gobierno de incoherencia en sus medidas y le pidió más concreción para saber de qué se habla & 132 \\
\hline 2 & $23-02-2010$ & Camps declara tener 905 euros en su cuenta corriente & 213 \\
\hline 3 & $24-02-2010$ & La Ley del Aborto entrará en vigor dentro de cuatro meses & 234 \\
\hline 4 & $25-02-2012$ & El Supremo abre un tercer proceso contra el juez Garzón & 90 \\
\hline 5 & $26-02-2010$ & La Fiscalía se opone a suspender a Garzón & 46 \\
\hline 6 & $27-02-2010$ & Los muertos tras el seísmo ascienden a 147 & 364 \\
\hline 7 & $28-02-2012$ & ETA, otra vez descabezada & 488 \\
\hline \multicolumn{4}{|c|}{ Elpaís.com } \\
\hline 8 & $22-02-2010$ & Aguirre ironiza: "Que nos den Economía y Trabajo. Otra cosa no sería pactar" & 466 \\
\hline 9 & $23-02-2010$ & Madrid olímpico en 2020 ó 2024 & 160 \\
\hline 10 & $24-02-2010$ & Dimite del comité de Tráfico un diputado del PP que conducía ebrio & 314 \\
\hline 11 & $25-02-2010$ & Los obispos no excomulgarán al Rey por firmar la Ley del Aborto & 543 \\
\hline 12 & $26-02-2010$ & Cinco disidentes toman el relevo de Zapata con una huelga de hambre & 186 \\
\hline 13 & $27-02-2010$ & El seísmo de Chile destruye más de medio millón de viviendas & 470 \\
\hline 14 & $28-02-2010$ & Rubalcaba"Han sido los peores meses para ETA" & 325 \\
\hline \multicolumn{4}{|c|}{ Lavanguardia.es } \\
\hline 15 & $22-02-2010$ & La final de la Copa del Rey de baloncesto fue la más vista de la historia & 307 \\
\hline 16 & $23-02-2010$ & El Banco de España pide proteger la economía con una "ambiciosa" reforma laboral & 201 \\
\hline 17 & $24-02-2010$ & Raúl Castro lamenta la muerte de Zapata y asegura que en Cuba "no existen torturados" & 264 \\
\hline 18 & $25-02-2010$ & Laporta empezará el lunes su carrera política & 134 \\
\hline 19 & $26-02-2010$ & Los autores del tiroteo a dos Mossos entraron en el piso haciéndose pasar por policías & 231 \\
\hline 20 & $27-02-2010$ & Un terremoto de 8,8 grados de magnitud sacude Chile y deja al menos 214 muertos & 164 \\
\hline 21 & $28-02-2010$ & El Sí gana con el $92,3 \%$ de votos frente al 2,7\% del No, en la segunda tanda de consultas independentistas & 399 \\
\hline
\end{tabular}

Tabla 4. Noticia más comentada por día y medio 
- "un abrazo a los bomberos de mi país, por su profesionalismo y su entrega [...]" (Víctor).

Los mensajes que responden a una retórica de diálogo se muestran mayoritariamente contrarios a comentarios previos. Los mensajes que expresan desacuerdo suponen el $80,7 \%$ de los comentarios de diálogo en Elpaís.com, el 78,1\% en Lavanguardia.es y el 54,6\% en Abc.es. Los que expresan acuerdo son superiores a los de desacuerdo sólo en un $10 \%$ de las noticias en las que se analizan los comentarios. dores es llamativa si se tiene en cuenta que los medios adoptan mecanismos de control

En la noticia sobre las declaraciones de Raúl Castro (n. 17), en Lavanguardia.es, destacan los comentarios de desacuerdo (25 de los 50 analizados). Dentro del desacuerdo, la "disconformidad" es mayoritaria $(57,4 \%)$. La existencia de mensajes descalificadores es significativa respecto a los mensajes de diálogo pues representan el 10,9\% en $A b c$. es, el $27,7 \%$ en Elpaís.com y el 38,1\% en Lavanguardia.es. Aunque la gravedad de los apelativos varía, la presencia de comentarios descalificadores es llamativa si se tiene en cuenta que los medios adoptan mecanismos de control. En la noticia donde se registra mayor número de comentarios descalificadores (n. 15), Lavanguardia.es publicaba:

- " [...] los comentarios deben respetar las Normas de participación [...]" (Moderación Lavanguardia.es).

Este mismo mensaje se encuentra en otras dos de las cinco noticias analizadas (n. 19 y n. 21). En la información del 28 de febrero se impide la participación desde las 20:21 horas:

- "[...] cerrado por incumplimiento de las Normas de participación [...]" (Moderación Lavanguardia.es).
La presencia de comentarios descalifica-

Entre las aportaciones de acuerdo, los mensajes de apoyo son mayoritarios en Abc.es (el $82 \%$ de estos) ${ }^{6}$ y en Elpaís. com (con el 68,8\%). En Lavanguardia.es se registra mayor presencia de mensajes de ayuda $(47,8 \%)$, concentrados casi en exclusiva en la noticia del día 27 . Son comentarios en los que los lectores ofrecen colaboración o soluciones a peticiones de otros usuarios como:

- “[...] Quisiera saber los daños en las carreteras de Chile [...]" (richram).

- "quisiera saber cuales fueron los daños en la sexta región [...]" (..... $x d)$.

Se observa escasa presencia del resto de categorías de acuerdo (el refuerzo representa el 8,9\% y la resolución el $7,9 \%$ ) y de desacuerdo (la aclaración suma el 6,7\%).

Destaca el reducido número de mensajes de intervención $(0,8 \%)$. El $50 \%$ se contabilizaron en Elpaís.com. Es significativo que en todos los casos se registran valoraciones negativas y se concentran mayoritariamente en críticas al medio ${ }^{7}$ :

- "Sres de La vanguardia informen más[...]" (Este, Lavanguardia.es, 27-02-2010).

- "si hubiera sido un diputado del PSOE la noticia no aparecería en El país" (Mariano, Elpaís.com, 24-02-2010).

- "Y en Gandesa no hay un juicio que debería de ser reportado cada dia en Abc...?[...] (Pa-co, Abc.es, 26-02-2010).

No obstante, en otro tipo de comentarios se presentan referencias tanto al diario como al sistema de medios de información con alusiones a la función de gatekeeper, al sistema de comentarios o a contenidos publicados para reforzar o completar la información. Algunos ejemplos son:

- "[...] Hay tres medios nacionales que no permiten un solo reproche a su línea política [...]" (Lazaro, Elpaís.com, 2402-2010).

- "[...] si dices algo serio van y te borran el comentario" (Miala, Abc.es, 28-02-2010).

- "Según reportajes de tv, los gitanos rumanos no los quieren ni en su país [...]" (Arandela, Lavanguardia.es, 26-022010).

\section{Conclusiones}

\begin{tabular}{|c|c|c|c|c|c|}
\hline $\begin{array}{c}\text { Tipo de } \\
\text { comentarios }\end{array}$ & Categoría & Subcategoría & $\begin{array}{c}\text { Comentarios } \\
\text { Abc.es } \\
(\mathrm{T}=346)\end{array}$ & $\begin{array}{c}\text { Comentarios } \\
\text { Elpaís.com } \\
(\mathrm{T}=\mathbf{3 5 0 )}\end{array}$ & $\begin{array}{c}\text { Comentarios } \\
\text { Lavanguardia.es } \\
(\mathrm{T}=350)\end{array}$ \\
\hline \multirow{3}{*}{ Participación } & Información & -- & 35 & 63 & 77 \\
\hline & \multirow{2}{*}{ Opinión } & Positiva & 37 & 47 & 34 \\
\hline & & Negativa & 161 & 154 & 132 \\
\hline \multirow{7}{*}{ Diálogo } & \multirow{4}{*}{ Acuerdo $^{3}$} & Ayuda & 1 & 1 & 11 \\
\hline & & Apoyo & 41 & 11 & 9 \\
\hline & & Refuerzo & 5 & 2 & 1 \\
\hline & & Resolución & 3 & 2 & 2 \\
\hline & \multirow{3}{*}{ Desacuerdo } & Aclaración & 9 & 2 & 3 \\
\hline & & Disconformidad & 39 & 42 & 39 \\
\hline & & Descalificación & 12 & 23 & 40 \\
\hline \multirow{6}{*}{ Intervención } & \multirow{2}{*}{ Referida al diario } & Positiva & 0 & 0 & 0 \\
\hline & & Negativa & 2 & 3 & 1 \\
\hline & \multirow{2}{*}{ Referida al artículo } & Positiva & 0 & 0 & 0 \\
\hline & & Negativa & 1 & 0 & 1 \\
\hline & \multirow{2}{*}{$\begin{array}{l}\text { Referida a un aspecto } \\
\text { específico }\end{array}$} & Positiva & 0 & 0 & 0 \\
\hline & & \begin{tabular}{|l|} 
Negativa \\
\end{tabular} & 0 & 0 & 0 \\
\hline
\end{tabular}

Tabla 5. Distribución de los comentarios de los usuarios por tipo, categoría, subcategoría y diario
Se observan diferencias en los mapas de participación en los medios analizados. Futuras investigaciones, con un análisis más extensivo, podrían registrar la incidencia que pueden tener en la participación factores diversos como la visibilidad, la permanencia en portada y la hora de actualización de los contenidos así como el propio perfil de la audiencia del medio. No obstante, los resultados obtenidos apuntan hacia la influencia que ejercen 
las estrategias editoriales de los diarios (que deciden en qué noticias permiten comentarios) y el interés de los usuarios por determinados contenidos. Así, el mayor alcance del comentario en Elpaís.com, como ya apuntara García-de-Torres et al. (2009), se justifica tanto por la menor apertura del diario como por el elevado número de comentarios registrados en las noticias. Por otra parte, el estudio confirma las hipótesis de partida. "Política" es el tema más popular en términos de participación. Asimismo, coincidiendo con el estudio de Martínez-Martínez (2011a), un acontecimiento de gran magnitud (el terremoto de Chile) genera gran número de contribuciones.

El estudio plantea la traslación de un tipo de cartas al director (Pastor, 2004; 2006; 2010) basada en los usos retóricos (Gomis, 1994) al análisis de otra forma de participación creativa del usuario: los comentarios a las noticias. Aunque el análisis muestra la presencia de los tres tipos de mensajes propuestos, los comentarios de participación son predominantes. Se puede hablar por tanto de un bajo índice de comunidad, es decir, de la escala que mide la relación que el usuario mantiene con el medio y con el resto de lectores y que incluiría una mayor presencia de mensajes de diálogo e intervención (Pastor, 2004). Los niveles descienden al hablar en términos de comunidad deseada pues esto implicaría eliminar los comentarios descalificadores (objetivo que parece escaparse a los medios a pesar de los mecanismos de control que emplean).

Prevalece el discurso crítico en los comentarios de los usuarios. La participación se construye mayoritariamente sobre la base de la oposición y el enfrentamiento canalizado en forma de opiniones negativas, contra-argumentaciones o actitudes contrarias al contenido de actualidad, a la postura adoptada por otro usuario o a la propia publicación. El terremoto de Chile, noticia de gran impacto, consigue superar esta tendencia en los tres diarios. Ante las repercusiones del acontecimiento los usuarios muestran su apoyo y solidaridad hacia las víctimas y comparten información para completar los datos que ofrecen los medios y responder así a las propias demandas de los lectores.

Aunque la "intervención" es residual entre los comentarios analizados, las alusiones a las prácticas que realizan los diarios o al sistema mediático se encuentran en distintos tipos de mensajes. La función de gatewatcher (Bruns, 2008) que desempeña el usuario impregna los comentarios en los que se critica a la publicación, los que mencionan las deficiencias en la selección de noticias, los que aluden a las limitaciones del sistema de comentarios y los que incluyen referencias indirectas a contenidos publicados por los medios permitiendo así reforzar una argumentación o completar la información.

\section{Notas}

1. Esta retórica de la participación es explicada por Gomis (1994, p. 63) a partir de la presencia de distintos elementos: "Los medios fomentan la participacion por medio de la pluralidad de escenarios y personajes y la agitación de símbolos cargados de emoción (...) Por encima de esta multiplicidad los sondeos hacen el papel de verdad revelada (...). Por otra parte, la participación se facilita también con recursos literarios y periodísticos, que sitúen al público y le ayuden a leer o escuchar (...)" (traducción del original en catalán).

2. Se exceptúan del análisis los reportajes especiales, contenidos de última hora (Armentia-Vizueta et al., 2000; Salaverría, 1997) y listados jerarquizados por la actividad del usuario pues pueden contener noticias cuya publicación no corresponda al día del análisis.

3. Los distintos grados de acuerdo hacen referencia al tipo de actitud o a la presencia de argumentos complementarios: la "ayuda" requiere la presencia de soluciones o una actuación a favor de un comentario; el "refuerzo", ampliar los argumentos; y la "resolución," una actitud conciliadora. La "aclaración" se diferencia de ésta pues mantiene un posicionamiento (frente a otro) pero incorpora elementos para reforzar o explicar esa posición de desacuerdo.

4. El cambio a Lavanguardia.com es posterior al análisis.

5. Limitaciones de este estudio exploratorio se derivan de la naturaleza cambiante y líquida (Bauman, 2000) de las portadas.

6. En este diario el mayor número de mensajes de apoyo (15) se contabilizan en la n. 1 y n. 7.

7. Comentarios de intervención negativos sobre artículos se registran en la n. 6 y la n. 16 .

"Política" es el tema más popular en términos de participación y un acontecimiento de gran magnitud (como el terremoto de Chile) genera gran número de contribuciones

\section{Nota de la Redacción}

La revista ha adaptado los comentarios a sus normas ortográficas y de estilo.

\section{Bibliografía}

Abdul-Mageed, Muhammad M. (2008). "Online new sites and journalism 2.0: reader comments on Al Jazeera Arabic". TripleC-cognition, communication, co-operation, v .6, n. 2, pp. 59-76.

http://www.triple-c.at/index.php/tripleC/article/view/78/70

Allan, Stuart; Thorsen, Einar (2009). Citizen journalism. New York: Peter Lang. ISBN: 9781433102950

Armentia-Vizueta, José-Ignacio; Caminos-Marcet, JoséMaría; Elexgaray-Arias, Jon; Martín-Murillo, Flora; Merchán-Mota, Iker (2000). El diario digital. Análisis de los contenidos textuales, aspectos formales y publicitarios. Barcelona: Bosch. ISBN: 8476767382

Bauman, Zygmunt (2000). Liquid modernity. Cambridge: Polity Press. ISBN: 0745624103

Bergström, Annika (2008). "The reluctant audience: online participation in the Swedish journalistic context". Westmins- 
ter papers in communication and culture, v. 5, n. 2, pp. 6080.

http://www.westminster.ac.uk/_data/assets/pdf file/0012/20019/005WPCC-Vol5-No2-Annika_Bergstrom.pdf

Bowman, Shayne; Willis, Chris (2005). Nosotros, el medio. Cómo las audiencias están modelando el futuro de las noticias y la información. The Media Center.

http://www.hypergene.net/wemedia/download/we media_espanol.pdf

Bruns, Axel (2008). Blogs, Wikipedia, Second life, and Beyond. From production to produsage. New York: Peter Lang Publishing. ISBN: 0820488666

De-Kerckhove, Derrick (1999). Inteligencias en conexión. Hacia una sociedad de la Web. Barcelona: Gedisa Editorial, 1999. ISBN: 9788474327526

Delclós, Tomàs (2012). "Los filtros de la moderación". Elpaís.com, 18 marzo.

http://elpais.com/elpais/2012/03/17/opinion/1332000900_296805. html

Díaz-Noci, Javier; Domingo, David; Masip, Pere; Micó, Josep-Lluís; Ruiz, Carles (2010). “Comments in news, democracy booster or journalistic nightmare: assessing the quality and dynamics of citizen debates in Catalan online newspapers". En: 10 th Int/ symposium on online journalism, 2010.

Domingo, David; Quandt, Thorsten; Heinonen, Ari; Pausussen, Steve; Singer, Jane B.; Vujnovic, Marina (2008). "Participatory journalism practices in the media and beyond: an international comparative study of initiatives in online newspapers". Journalism practice, v. 2 n. 3, pp. 326-342. http://jclass.umd.edu/classes/jour698m/domingo.pdf

Eco, Umberto (1974). La estructura ausente. Barcelona: Editorial Lumen. ISBN: 8426410766

http://www.upv.es/laboluz/leer/books/eco_estructura_ ausente.pdf

Fondevila-Gascón, Joan-Francesc (2012). "El uso de recursos del periodismo digital en la prensa del Reino Unido, Francia, Estados Unidos y España". Estudios sobre el mensaje periodístico, v. 18, n. 1, pp. 73-87.

http://revistas.ucm.es/index.php/ESMP/article/view/39355 http://dx.doi.org/10.5209/rev_ESMP.2012.v18.n1.39355

García-de-Torres, Elvira; Martínez-Martínez, Silvia; Cebrián, Bernardino; Rodríguez-Martínez, Janet; Albacar-Serrano, Helena (2009). "La agenda de los usuarios: un análisis de la participación en la página principal y la selección local de Elpaís.com y 20minutos.es". En: Pérez, Pilar; Rivas, Pedro y Gelado, Roberto (Coord.). Estudios de periodística XIV. Periodismo ciudadano, posibilidades y riesgos para el discurso informativo: comunicaciones y ponencias del $X$ Congreso de la Sociedad Española de Periodística, pp. 287-300. ISBN: 978 8472998421

García-de-Torres, Elvira (coord.) (2012). Cartografía del periodismo participativo. Valencia: Tirant Humanidades, pp. 189-221. ISBN: 9788415442189

Gillmor, Dan (2004). We the media. Sebastopol: O'Reilly, 2004. ISBN: 0596007337
Gomis, Lorenzo (1991). Teoría del periodismo: cómo se forma el presente. Barcelona: Paidós. ISBN: 8475096557

http://es.scribd.com/doc/52513244/Teoria-Del-PeriodismoComo-Se-Forma-El-Presente-Lorenzo-Gomis

Gomis, Lorenzo (1994). "Persuadir la gent de que passen coses interessants". Periodística, n. 7, pp. 59-64.

http://www.raco.cat/index.php/Periodistica/article/ view/245761/329036

Haas, Tanni (2010). “Open source interview: online dialogue, public life and citizen journalism". En: Rosenberry, Jack; St.John, Burton. Public journalism 2.0, New York: Routledge. pp. 126-132. ISBN: 0415801834

Hermida, Alfred (2011). "Mechanism of participation: how audience options shape the conversation". En: Singer, Jane B. et al. Participatory journalism. Guarding open gates at online newspapers. United Kingdom: Wiley-Blackwell, pp. 13-33. ISBN: 9781444332278

Jenkins, Henry (2008). Convergence culture: where old and new media collide. Barcelona: Paidós. ISBN: 8449321530

Lasica, Joseph D. (2002). "The promise of Daily me”. Online journalism review, April.

http://www.ojr.org/ojr/lasica/1017779142.php

Martínez-Martínez, Silvia (2011a) "The news as object of global conversation: the audience participation in the diffusion and interpretation processes of the journalistic information". En: Ecrea digital culture and communication $3^{\text {rd }}$ workshop.

Martínez-Martínez, Silvia (2011b). "Retrato de la irrupción de la web 2.0 en la prensa local española (2006-2008): mapa de las tendencias en la incorporación de recursos por CCAA". En: XI Congreso de comunicación local: la prensa local ante el reto digital.

Martínez-Martínez, Silvia (2012). "Las herramientas de participación en la prensa digital de España". En: García-deTorres, Elvira (Coord.). Cartografía del periodismo participativo. Valencia: Tirant Humanidades, pp. 189-221. ISBN: 978 8415442189

Masip, Pere; Díaz-Noci, Javier; Domingo, David; MicóSanz, Josep-Lluís; Salaverría, Ramón (2010). “Investigación internacional sobre ciberperiodismo: hipertexto, interactividad, multimedia y convergencia". El profesional de la información, nov.-dic., v. 19, n. 6, pp. 568-576.

http://dspace.unav.es/dspace/handle/10171/13561 http://dx.doi.org/10.3145/epi.2010.nov.02

Merrill, John C. (1999). “The global elite. World's best newspapers reflect political changes". IPI report, n. 4.

Newhagen, John E.; Levy, Mark R. (1996). Distributed communication architectures and news. The future of journalism in a distributed communication architecture.

Nip, Joyce Y. M. (2010). "Routinization of charisma: the institutionalization of public journalism online". En: Rosenberry, Jack; St. John, Burton. Public journalism 2.0: the promise and reality of a citizen engaged press. New York: Routledge, pp. 135-148. ISBN: 0415801834 
Papacharissi, Zizi (2009). Journalism and citizenship. New agendas in communication. New York: Routledge. ISBN: 0415804981

Pastor, Lluís (2004). Teoría de las cartas al director. El papel del lector en la prensa. Barcelona: Univ. Ramon Llull.

Pastor, Lluís (2006). "Un análisis de las cartas al director en diarios de referencia internacional". Comunicación y sociedad, v. 19, n. 1, pp. 129-158.

http://www.unav.es/fcom/comunicacionysociedad/es/ resumen.php?art_id $=59$

Pastor, Lluís (2010). Teoría de las cartas al director. La gestión periodística del público 1. Barcelona: Editorial UOC. ISBN: 9788497889506

Pérez-Oliva, Milagros (2009). "Comentarios muy poco edificantes". Elpaís.com, 20 diciembre.

http://elpais.com/diario/2009/12/20/opinion/1261263605_850215. html

Reich, Zvi (2011). "User comments. The transformation of participatory space". En: Singer, Jane B. et al. Participatory journalism. Guarding open gates at online newspapers. United Kingdom: Wiley-Blackwell, pp. 96-117. ISBN: 978 1444332278

Ruiz, Carlos; Masip, Pere; Micó-Sanz, Josep-Lluís; DíazNoci, Javier; Domingo, David (2010). "Conversación 2.0. y democracia. Análisis de los comentarios de los lectores en la prensa digital catalana". Comunicación y sociedad, v. 23, n. 2, pp. 7-39. http://www.unav.es/fcom/comunicacionysociedad/es/ articulo.php?art_id=360

Ruiz, Carlos; Domingo, David; Micó-Sanz, Josep-Lluís; DíazNoci, Javier; Meso, Koldo; Masip, Pere (2011). "Public sphere 2.0? The democratic qualities of citizen debates in online newspapers". The intl journal of press/politics, v. 16, n. 4, pp. 463-487.

http://dx.doi.org/10.1177/1940161211415849

Salaverría, Ramón (1997). “Aproximación a los orígenes de la preceptiva sobre escritura periodística (1840-1940)". Comunicación y sociedad, v. X, n. 1, pp. 61-95.

http://www.unav.es/fcom/comunicacionysociedad/es/ articulo.php?art_id=161

Schaffer, Jan (2010). "Open source interview: civic and citizen journalism's distinctions". En: Rosenberry, Jack; St. John, Burton. Public journalism 2.0: the promise and reality of a citizen engaged press. New York: Routledge, pp. 176-182. ISBN: 0415801834

Singer, Jane B. (2006). "The socially responsible existentialist. A normative emphasis for journalists in a new media environment". Journalism studies, v. 7, n. 1, pp. 2-18. http://dl.franko.Iviv.ua/medialiteracy/socially_res.pdf http://dx.doi.org/10.1080/14616700500450277

Singer, Jane B.; Ashman, Ian (2009). "User-generated content and journalistic values". En: Allan, Stuart; Thorsen, Einar. Citizen journalism, New York, Peter Lang, pp. 233-242. ISBN: 9781433102950

\section{Próximos temas centrales}

Mayo 2013

Julio 2013

Septiembre 2013

Noviembre 2013

Enero 2014

Marzo 2014

Mayo 2014
Bibliotecas y documentación de museos

Economía de la información

Gestión de contenidos

Formación y aprendizaje

Documentación audiovisual

Políticas de información

Humanidades digitales

Los interesados por favor consulten detenidamente las Normas para autores: http://www.elprofesionaldelainformacion.com/autores.html

y luego envíen sus artículos a través del gestor de manuscritos OJS de la plataforma del Recyt: http://recyt.fecyt.es/index.php/EPI/index 